\title{
Antecedents of BPR Success in Manufacturing Firms
}

\author{
T. Guimaraes \\ Tennessee Technological University \\ Cookeville, TN 38501 \\ U.S.A. \\ Telephone (615)372-3385, FAX (615)372-6249 \\ e-mailTG5596@TNTECH
}

\begin{abstract}
Business Process Reengineering has been touted by many as dramatic improvements necessary for organization competitiveness, but in practice there are many unsuccessful cases. Thus, there is need for a more systematic and rigorous assessment of the factors deemed important to project success. That is the main objective of this study. In this case, success has been defined in three different ways: goals and objectives accomplished by the project, benefits derived from the project, and its impact on company performance. Based on the results, recommendations are made for managers to focus attention and resources on factors important to success, and to proceed in a fashion which minimizes the risk of failure. The point of entry into the companies participating in this study were internal auditing directors and comptrollers (IA's). Questionnaires were mailed to the IA's of 586 randomly selected manufacturing organizations. The usable sample of 135 questionnaires represent a 22 percent response rate. In general, organizations are not emphasizing some of the most important activities and tasks recommended in the BPR literature, such as changes to customer/market related business processes, the value-added element of every business activity, and applying the right innovative technology. Based on the findings as a whole, it behooves top managers not to engage in BPR before ensuring the presence of the success factors found to be important.
\end{abstract}

Keywords
Business Process Reengineering, Success Factors

\section{BACKGROUND}

The manufacturing sector accounts for the bulk of corporate research and carries the most weight in international balance of payments. It remains what has been called the locomotive that pulls the other sectors of the economy along' (Faltermayer, 1993). Regardless of the great importance of manufacturing, its success or failure is far from assured. In spite of having substantial mechanization and automation, the most productive workers in the world, and greater access to natural resources than perhaps any other nation, U.S. manufacturing has fallen behind (Miske, 1992). According to a Commerce Department revision in 1992, the value 
added by manufacturing slipped from $20.7 \%$ of GNP in 1979 to $19.7 \%$ a decade later. A most distressing result of that recalculation was that the improvement in manufacturing productivity in the 1980's is found to be substantially less impressive than advertised earlier: $2.4 \%$ growth per year on average instead of 3.1\% (Faltermayer, 1993). On the other hand, the manufacturing sector is thought to be regaining its ability to become more productive (Howard, 1994). The erosion of our manufacturing base and the loss of initiative to Japan and Europe have been reversed. From 1982 to 1990 , the productivity of U.S. manufacturing workers increased $4.5 \%$ per year, a record for any period since the end of World War II (Howard, 1994). In the process of exploring the basic differences between the Japanese and American manufacturing management approaches and applying a host of new methods and techniques, many U.S. firms have been redefining the nature of their businesses (Patterson \& Harmel, 1992).

The main emphasis worldwide over the past decade has been on improving quality. Many companies have adopted a new management and operations philosophy widely known as Total Quality Management (TQM). The major underpinnings of TQM are a continuous effort to improve products, processes, and operations to better satisfy customer needs; employee empowerment in decision making and a team approach to identify, prioritize, and change targets for improvement; and a company-wide commitment to TQM strong enough to change what is necessary, including organization values and culture.

The modern view of quality holds that it is not sufficient for product attributes to meet customer requirements; they must exceed them (Ramberg, 1994). Those American corporations who have embraced the principles of Total Quality are saying that everybody inside the company should be focused on the customer - not just the marketing department and the sales force; not just those on the production line who now need to understand customer specifications; not just the Chief Executive Officer (CEO) as he visits and spends time with customers. Today everyone, including staff functions like public relations, should be keenly focused on the companyfls customers (Oliver, 1990).

Although there has been a significant amount of success with TQM, companies are now realizing the need for more dramatic improvements in productivity, competitiveness and profitability. This can be accomplished by major paradigm shifts which focus on value-added activities as well as other underpinnings for successfully implementing the concept of Business Process Reengineering (BPR) (Goll \& Cordovano, 1993; Teng, Grover \& Fiedler, 1994). The results of a 1992 Price Waterhouse survey of the manufacturing industry in the mid-Atlantic region reported that more than 80 percent of the respondents were currently reengineering, in the planning stages or seriously considering it (Goll \& Cordovano, 1993). Another survey of over 500 CIOs given by Deloitte and Touche revealed that the average CIO is involved in 4.4 reengineering projects up from an average of 1.6 in 1992 (Moad, 1993).

Essentially, BPR amounts to making radical changes to one or more business processes affecting the whole organization. It also requires a cross-functional effort usually involving innovative applications of technology. Reengineering is a pioneering attempt to change the way work is performed by simultaneously addressing all the aspects of work that impact performance, including the process activities, the peoplefls jobs and their reward system, the organization structure and the roles of process performers and managers, the management system and the underlying corporate culture which holds the beliefs and values that influence everyonefls behavior and expectations (Cypress, 1994). With BPR, rather than simply eliminating steps or tasks in a process, the value of the whole process itself is questioned (Gotlieb, 1993).

BPR differs from TQM in two important respects. First, while TQM is focused on continuous improvement, an incremental performance improvement approach, reengineering was founded on the premise that significant corporate performance improvement requires discontinuous improvement - breaking away from the outdated rules and fundamental assumptions that underlie operations. Second, reengineering makes a significant break with previous performance improvement approaches by requiring a high level of state-of-the-art 
information technology awareness among the entire reengineering team prior to, rather than after, the definition of process changes or improvements (Cypress, 1994). Some technologies (i.e. imaging systems and expert systems) can provide substantial opportunities for the redesign of business processes (Guimaraes, 1993). Again, for each technology application, success is far from guaranteed.

Indeed, a thorough understanding of a particular technology's success factors is critical to reduce the risk of project failure, particularly in the fast pace, high pressure usually associated with BPR projects (Yoon, Guimaraes \& O'Neal, 1995; Yoon, Guimaraes \& Clevenson, 1995).

Many organizations that have undertaken reengineering projects reported significant benefits from their BPR experience (Cafasso, 1993b) in several areas such as: customer satisfaction, productivity and profitability (The Economist, 1993; Goll \& Cordovano, 1993). The expected improvements vary dramatically by company: productivity, quality, profits and customer satisfaction are expected to improve from $7 \%$ to $100 \%$, depending on where the company is starting from and the extent of its efforts. Improvements forecast in costs, inventory, cycle time and response tíme range from $10 \%$ to as much as $400 \%$. Other benefits include: reduced floor space requirements; reduced labor requirements, particularly indirect labor; reduced material handling; improved employee empowerment and morale; improved communications between operations; and improved quality (Farmer, 1993). An extensive list of BPR benefits has been compiled and empirically rated by the author elsewhere (Guimaraes, 1995).

While the promises from BPR implementation seem impressive, the problems are also numerous. Although many firms have implemented a variety of reengineering programs over the past years, relatively few have reaped the benefits they expected (Cummings, 1993; Guimaraes, 1995). According to CSC Index, approximately one fourth of 300 reengineering projects in North America are not meeting their goals and the authors speculated that the figure may be closer to 70\% (Cafasso, 1993a). Many CIOs say that the actual benefits of the projects fall short of their expectations along the dimensions of customer service, process timeliness, quality, cost reduction, competitiveness, new/improved technology and sales/revenues (Hayley, Plewa \& Watts, 1993). A Deloitte \& Touche survey showed reengineering projects consistently fall short of their expected benefits (Moad, 1993). The up-front costs are high, particularly in the areas of training and consultant fees, with a time consuming learning curve (Bozman, 1992).

For some companies, creating an environment in which reengineering will succeed may be exceedingly difficult (Grover, et al, 1993). Some argue in favor of more gradual departures from traditional practices since managerial innovations take time and induce substantial strain on the organization (Brown, 1993). As discussed by Guimaraes, Bell and Marston (1993) in the context of organizational change in general, there is much business organizations can do to reorganize for fast changing environments. The changes often fail because worker habits are not addressed during implementation (Grover, et al, 1993). Succumbing to the pressure to produce quick results, many managers who implemented BPR tend to ignore the massive changes in organizational structure, have misused and alienated middle managers and lower level employees, sold off solid businesses, neglected important research and development, and hindered the necessary modernization of their plants (Cascio, 1993). An extensive collection of implementation problems encountered in practice has been tested by this author elsewhere (Guimaraes, 1995). As these studies indicate, all is not well with the Business Process Reengineering (BPR) bandwagon.

There is need for a better understanding of the factors which affect probability of BPR project success. To that effect, this study targeted manufacturing organizations with the major objective of identifying and rating the importance of factors proposed as important for successfully implementing BPR. Based on the results, recommendations are made for managers to focus attention and resources on factors important to success, and to proceed in a fashion which minimizes the risk of failure. 


\section{THE THEORETICAL FRAMEWORK}

\section{The Major Constructs}

BPR Success Factors. The literature contains an abundance of personal opinions on what are important factors to BPR success, some of which sound like self-serving statements, such as the need to bring in specialists for the particular industry. Most of the factors discussed make common sense, such as the need for the BPR project to be driven by customer demand, competitive pressures, and the need to improve financial performance (Goll \& Cordovano, 1993), and/or relationships with suppliers (O'Leary, 1993). The need for education and reeducation is also widely recognized. Employees must be taught what the reengineering process actually is, how it differs from known work patterns and what role they will play in it (Goll \& Cordovano, 1993). Managers are also encouraged to reconsider mechanisms for reward and recognition to keep the reengineered organization moving forward, to instill in people the willingness to share information, and to use hands-on experience in redesigning new processes (Goll \& Cordovano, 1993). Farmer (1993) proposes several important factors: the use of project champions; having an organized and well-disciplined plan of attack; employing a rigorous and detailed analysis process to develop a rough-cut design and identify major issues; avoiding the selection of traditional thinkers as team members; carefully setting up details, tooling, scheduling, maintenance, storage, etc., before implementation; having a defined project organization structure and regularly scheduled meetings of the project manager with every level of this structure to focus attention; using process mapping to distinguish productive activities from those that are non-value-added (Curtis et al., 1992); and clearly defining and communicating the mission and vision of the project.

Gulden \& Reck (1992) also have a list of important factors: because reengineering results in large-scale changes to a business process, organizational structures, management systems, and values, executives must carefully target only a few critical (though crossfunctional) business processes; they should correct organizational procedures that are focused on satisfying internal demands rather than the marketplace; and focus on outcome rather than task. Other factors which have been proposed are that: the technology be viewed as an enabler, not a solution (Huff, 1992); let doers be the decision makers (Hammer, 1990); use automation to reduce costs and response times (Green, 1992); do not compromise on the need for quality improvements (Faier \& Shen, 1992; Knorr, 1991); project initiated and led from the top-down by company top management willing to be accountable for project success (Knorr, 1991; Freiser, 1992); use surveys to find out what's working and what's not; be completely open about what you're doing, when and why (Rasmus, 1992; Margolis, 1992); and adopt an integrated approach to IT and business planning (Grover et al., 1993). The list of success factors collected from the literature was grouped, and each individual item was rated as shown in Table 1.

In this study BPR success has been defined in three different ways: the extent to which the project accomplished its goals and objectives, provided specific benefits, and improved specific dimensions of company performance. 
Table 1 Classification For BPR Success Factors

\section{EXTERNAL:}

1. Use industry specialists and outside assistance

Mean

2. BPR motivated by customer demands and competitive pressures

$\begin{array}{rr}2.84 & .92 \\ 3.48 & 1.13\end{array}$

\section{EMPLOYEE EMPOWERMENT:}

1. Reeducate and retrain workers on what BPR actually is

2. Empower workers so that doers are decision makers

$2.96 \quad 1.04$

\section{OPERATIONAL:}

1. Use resources effectively

$4.18 \quad .71$

2. Implement new processes as planned and on schedule

3. Develop a defined project organization

4. Target only a few critical (though cross-functional) business processes

5. View technology as an enabler, not as a solution

6 . Reduce cost and response times by automation

7. Desire for continuous performance improvement

$3.18 \quad 1.14$

8. Adopt an integrated approach to IT and business planning

$3.13 \quad 1.15$

\section{COMMUNICATION:}

1. Share and exchange information willingly

2. Schedule meetings between project manager and each level of project structure regularly

3. Develop and communicate clear written mission and vision statements

4. Create an enabling charter that describes the BPR program and support of management

5. Use surveys to determine what's working and what's not

\section{METHODS AND TOOLS:}

1. Utilize hands-on experience in reengineering diverse processes

2 . Use concept design phase to develop a rough-cut design and to identify major issues

3. Determine all setup details, tooling, scheduling, maintenance, storage, replenishment, quality, etc. before implementation

4. Simplify material flow, logistics, planning, and other distinct operations by using group technology

5. Use process mapping to distinguish productive activities from non-valueadded activities

6. Revise procedures that focus on satisfying internal demands rather than the marketplace

7. Focus on the outcome rather than task

$4.21 \quad .66$

$\begin{array}{ll}4.14 & .66 \\ & .84\end{array}$

\section{LEADERSHIP:}

1. BPR initiated and led from the top-down by senior-level management

2. BPR motivated by chief executive willing to be held accountable for project success

BPR Goals and Objectives Accomplished. The primary objective of BPR is to make business organizations more competitive by improving quality, reducing costs and shortening product development cycles (Dagres, 1993; Grover et al., 1993). BPR's distinguishing characteristics are radical change, cross-functionality, operating across organizational units, 
breaking outdated paradigms, and involves innovative application of technology (Tsang, 1993). The change process itself should emphasize the value-added element for every activity, recognizing time as a competitive weapon, focusing on end results and objectives, ensuring quality at the source, planning for an end-to-end solution, challenging the old ways and proposing new ways, using the right technology, empowering people and building consensus on making changes, and setting aggressive goals for the new process (Stadler, 1992). The right idea for BPR is to look at the end- to-end processes that are really important to a company's success, then rapidly redesign who does what and give workers new tools to get more done (Moad, 1993). It is a new way to think about information technology, in terms of how it supports new or redesigned business processes, rather than business functions or other organizational entities (Davenport, 1990). Based on this literature survey, a list of potential BPR projects goals and objectives were collected. Table 2 indicates the extent to which such goals were actually accomplished by the projects in the sample.

Derived Benefits. Many organizations have reported significant benefits from their BPR experience (Cafasso, 1993b). In the case of Allnet Communications Services Inc., one of the nation's largest providers of long distance service, the reengineered processes are said to be much more efficient in terms of machine resources with significant decreases in processing time and input/output activity, and fulfillment of the promise of dramatically improving business performance (Kador, 1992). Some authors have reported major improvements in customer satisfaction, productivity and profitability at companies that have undertaken reengineering projects (The Economist, 1993; Goll \& Cordovano, 1993).

The expected improvements vary dramatically by company: productivity, quality, profits and customer satisfaction are expected to improve from $7 \%$ to $100 \%$, depending on where the company is starting from and the extent of its efforts. Improvements forecast in costs, inventory, cycle time and response time range from $10 \%$ to as much as $400 \%$. Other goals were given as $100 \%$ on-time deliveries and zero loss of market share (Goll \& Cordovano, 1993). When creatively applied, the new processes result in dramatic improvements. Other benefits include: reduced floor space requirements; reduced labor requirements, particularly indirect labor; reduced material handling; improved employee empowerment and morale; improved communications between operations; and improved quality (Farmer, 1993). BPR requires teams of people to implement new procedures and programs. These also help improve relationships with customers and suppliers, empower employees, and improve products and processes (Gulden \& Reck, 1992). Reengineering by restructuring sales teams by product and industry are useful to meet the needs of unique customer groups and to respond faster to customer requests (Faier \& Shen, 1992).

Table 2 Extent BPR project goals and objectives were accomplished

1. Increased own competitiveness by improving quality

2. Increased own competitiveness by reducing costs Mean St.D

3. Emphasized the value-added element at every activity

4. Used time as a competitive weapon

$2.81 \quad .73$

5. Focused on end results and objectives

$3.11 \quad .79$

6. Applied the right innovative technology

$3.22 \quad .84$

7. Built consensus on making changes

$2.87 \quad .72$

8. Met aggressive business process goals

3.23

2.29

9. Redesigned end-to-end processes important to company's success

10.Process improvements are based on capabilties of information technology

11.Operating effectively across organizational units 
The highest realized benefits are for improved customer service, faster processes and increased quality, while the lowest improvements are increasing sales and revenue (Cummings, 1993]. USAA, a large financial services company, is said to be quite successful at business reengineering, with a program of continuous business process review and redesign which looks at every department at least once every two years. One result is that the company is well along the path to becoming a paperless organization [Fitzpatrick, 1992]. Other benefits derived from BPR include: major reductions in process cost and execution time, and major improvements in the quality of process outcomes [Stadler, 1992]. Based on the literature, the list of BPR benefits addressed in this study are presented in Table 3.

Table 3 BPR benefits

1. Machine resources (more efficient use)

Mean St.D

2. Customer satisfaction (quicker response to customer requests)

.75

3 . Productivity (decreased cycle time, inventory, or cost)

$3.55 \quad .76$

4. Profitability (increased economic growth

$3.14 \quad .77$

5. Quality (improved products/services and related information)

$2.93 \quad .67$

6. Labor resources (improved employee morale and productivity)

$2.81 \quad .59$

7. Sales team (focused resources to meet needs of unique customer groups) 3.39

8. Information technology (improved to quickly address customer changes) $2.57 \quad .64$

9. Sales and marketing processes (more cost-effective)

2.80

.74

Scale: 1=Not at all, 2=Minor Extent, 3=Moderate Extent, 4=Major Extent, 5=Great Extent

Table 4 BPR's impact on company performance

1. Sales growth rate

Mean St.D

2. Market share

$2.43 \quad .64$

3. Operating profits

$2.64 \quad .71$

4. Rates of profits to sales

$2.88 \quad .94$

5. Cash flow from operation

$2.59 \quad .80$

6 . Return on investment

$2.84 \quad .72$

7 . New product development

$2.67 \quad .72$

8. New market development

9. R \& D activities

10.Cost reduction program

$2.47 \quad 1.19$

11.Personnel development

12.Political/public affairs

$3.02 \quad .71$

Scale: 1=Not at all, 2=Minor Extent, 3=Moderate Extent, 4=Major Extent, 5=Great Extent

Organization Performance. When actually encountered in practice the many possible business benefits from reengineering hopefully will translate into improved company performance. Therefore, the latter should be considered the ultimate measure and dependent variable for studies assessing the overall benefits from substantial reengineering projects. Company performance can be measured in a wide variety of ways (Steers, 1977; Venkatraman \& Ramanujam, 1986; Snow \& Hrebniak, 1980). Many authors have used one item to measure company performance, such as company profitability (return on total assets) (Snow \& Hrebniak, 1980). Given the wide diversity of possible benefits from company innovativeness 
and the need for content validity, studies assessing the impact of innovation on company performance should use multi-dimensional scales. In this study, the 12 company performance dimensions shown in Table 4, which were previously validated by Gupta and Govindarajan (1984) have been used to measure the payoffs from company innovativeness.

\title{
3 METHODOLOGY
}

\begin{abstract}
Sampling Method
The point of entry into the companies participating in this study were through their internal auditing directors/comptrollers (IA's). Questionnaires were mailed to the IA's of 586 randomly selected manufacturing organizations. A total of 152 responses were received within the specified time, however 17 had to be discarded due to missing data (12), invalid responses (2), and responses based on BPR projects which did not meet specified qualifications (3). The usable sample of 135 questionnaires represents a $22 \%$ response rate which is considered satisfactory for exploratory studies of this type. BPR was defined as dramatic changes (paradigm shifts) to business processes, in contrast with incremental improvements. Further, respondents were explicitly asked, unless otherwise indicated, to address the most recent BPR project which has been in operation for at least one year. To protect the respondents, they were promised complete anonymity and that only aggregate information on participants would be made public. A self- addressed, stamped envelope was provided for questionnaire return directly to the author.
\end{abstract}

\section{Sample Description}

The respondents represent companies at several levels of gross revenue, with few $(1.5 \%)$ having revenues below $\$ 50$ million, and most $(74.8 \%)$ having revenues above $\$ 300$ million. Furthermore, many of the firms operate globally thus enabling the results to be generalized to the same scale. The list of general business processes areas addressed in this study are shown in Table 5. On the average, sales/order entry, production scheduling/planning, and product design/development were the business processes changed to the greatest extent. Surprisingly, given the widespread attention to customer satisfaction shown in press, on the average the customer service process has been changed to the lowest extent.

\section{Construct Measurement}

Respondents rated all items comprising the constructs below using the scale 1 (not at all), 2 (to a minor extent), 3 (to a moderate extent), 4 (to a large extent), and 5 (to a great extent). The average rating for the respective sub-items represents the overall measure for each construct.

Success Factors. The factors were not combined to represent a major success factors construct. Further, statistical factor analyses produced nonsensical factor subgroups with no recognizable meaning. Therefore, subsequent analyses either use the items individually or subgrouped intuitively as shown in Table 1 which contains the average rating and standard deviation for each item across the sample.

Goals and Objectives Accomplished. The respondents were asked to rate the extent to which the project goals and objectives were actually accomplished. The average ratings and the standard deviation for each item across the sample are shown in Table 2. For each respondent, these items were averaged to produce a measure for the extent to which the BPR project goals and objectives were accomplished. The Cronbach's Alpha coefficient of internal reliability for this scale was .82 . 
Table 5 Degree of operational change to business processes

1. Customer service (after sale services)

Mean St.D

2. Sales/order entry (selling and entering orders)

3. Invoicing/billing (generation and mailing of invoices/bills)

2.71

3.50

.85

4. Purchasing (ordering from suppliers)

2.80

2.92

2.78

2.68

6. Pricing

7. Marketing research

2.70

3.40

3.36

2.76

3.38

8. Product design/development

9. Distribution (transporting goods to market)

10.Business planning

11.Inventory management (keeping inventories at planned levels)

12.Quality management (measuring/monitoring/taking action to maintain quality)

2.72

3.42

2.88

13.Production scheduling/planning (for manufacturing requirements)

14.Personnel management

Scale: 1=Not at all, 2=Minor Extent, 3=Moderate Extent, 4=Major Extent, 5=Great Extent

Derived Benefits. A list of 9 major potential benefits from BPR implementation proposed in the literature were provided for respondents to rate the extent to which each has been derived from the particular reengineering changes. The average ratings and the standard deviation for each item across the sample are shown in Table 3. For each respondent, these items were averaged to produce a measure for benefits derived from the BPR project. The Cronbach's Alpha coefficient of internal reliability for this measure was .82 .

Impact on Organization Performance. This was measured along the 12 dimensions proposed by Gupta and Govindarajan (1984) which are shown in Table 4 . The average ratings and the standard deviation for each item across the sample are shown in Table 4. For each respondent, these items were averaged to produce a measure for the extent to which the BPR project affected the company's business performance. The Cronbach's Alpha coefficient of internal reliability for this scale was .82 .

\section{Validity of the Measures}

Despite the exploratory nature of this study, several precautions were taken to ensure the validity of the measures used. Many of the recommendations by Carmines and Zeller (1979) were followed. To ensure content validity, a thorough survey of the relevant literature was undertaken to understand the important aspects of each major construct and its components, and not to neglect any important dimension. To further reduce the possibility of non-random error, the main source of invalidity, a group of six practitioners with substantial experience managing major business organization changes, reviewed the questionnaire for validity (measuring the phenomena intended), completeness (including all relevant items), and readability (making it unlikely that subjects will misinterpret a particular question). A few items were added to constructs in the questionnaire and some questions were reworded to improve readability; otherwise, the items composing each major construct remained as derived from the literature.

\section{Reliability of the Measures}

Given the lack of a theoretical basis for the BPR phenomenum, only one of the measures (organization performance) has been previously used and its psychometric properties are relatively well known. The internal consistency reliability coefficients (Cronbach's alpha) for 
the three scales used in this study are all well above the level of .50 acceptable for exploratory studies (Nunally, 1978).

\section{Data Analysis}

The statistical computations for this study are fairly simple and straight forward. Arithmetic means and standard deviations were computed for the success factors and the items in the major constructs. Pearson's correlation coefficients were computed to measure the strength of the relationships between each success factor and the three measures for BPR success.

\section{RESULTS}

\section{The Ratings For Success Factors Importance}

As discussed earlier and shown in Table 1, the success factors have been intuitively classified by the author into six categories: external, employee empowerment, operational, communication, methods and tools, and leadership factors. According to the results, having the BPR project motivated by customer demand and competitive pressure, on the average, is considered to be more important for project success than the use of industry specialists or other outsiders. Similarly, reeducating and retraining workers on what BPR actually is, is deemed more important than empowering the workers performing the required tasks as decision makers. In terms of operational factors, developing a defined project organization and using resources effectively are considered to be very important. The relatively lower standard deviations for these two items indicate that individual respondents are in closer agreement on their ratings. In the communication area, scheduling regular meetings for project managers and each level of the project structure, and sharing and exchanging information willingly (the primary reason for having such meetings) are deemed very important. Methods and tools considered to be very important are the revision of procedures that focus on internal demands rather than the marketplace, a BPR project focus on outcomes rather than tasks, and regular meetings between project managers and all levels of the project organization. Both items under Leadership were rated as very important on the average.

\section{Rating Project Goals And Objectives, And Antecedent Success Factors}

Contrary to the opinion of many BPR critics, Table 2 suggests that on the average, companies who have implemented BPR projects have accomplished, at least to a moderate extent, some important project goals and objectives, including: operating effectively across organizational units, built consensus on changes made, and redesigned end-to-end processes important to the company success. While some of the items show relatively large standard deviations indicating considerable company to company variance around the arithmetic mean, on the average companies are accomplishing all the enumerated goals and objectives somewhere between to a minor extent' and 'to a major extent.'According to Table 6, the most important (Pearson's coefficients are higher and significant at the .01 level or better) success factors for accomplishing BPR project goals and objectives are empowering workers as decision makers, implementing new processes as planned and on schedule, targeting a few critical business processes, sharing information willingly, using surveys to determine what is working, determining all set up details before project implementation, revising procedures dealing with internal demands, and ensuring that the chief executive in charge is willing to take responsibility for project success. 
Table 6 Factors important to BPR success

EXTERNAL:

1. Use industry specialists and outside assistance

2. BPR motivated by customer demands and competitive pressures EMPLOYEE EMPOWERMENT:

1. Reeducate and retrain workers on what BPR actually is

2. Empower workers so that doers are decision makers

OPERATIONAL:

1. Use resources effectively

2. Implement new processes as planned and on schedule

3. Develop a defined project organization

4. Target only a few critical (though cross-functional) business processes

5. View technology as an enabler, not as a solution

6. Reduce cost and response times by automation

7. Desire for continuous performance improvement

8. Adopt an integrated approach to IT and business planning

\section{COMMUNICATION:}

1. Share and exchange information willingly

2. Schedule meetings between project manager and each level of project structure regularly

3. Develop and communicate clear written mission and vision statements

4. Create an enabling charter that describes BPR program and support of management

5. Use surveys to determine what is and is not working

\section{METHODS AND TOOLS:}

1. Utilize hands-on experience in reengineering diverse processes

2. Use concept design phase to develop a rough-cut design and to identify major issues

3. Determine all setup details, tooling, scheduling, maintenance, storage, replenishment, quality, etc.before implementation

4. Simplify material flow, logistics, planning, and other distinct operations by using group technology

5. Use process mapping to distinguish productive activities from non-value-added activities

6. Revise procedures that focus on satisfying internal demands rather than the marketplace

7. Focus on the outcome rather than task

LEADERSHIP:

1. BPR initiated and led from the top-down by senior-level management

2. BPR motivated by chief executive willing to be held accountable for project success

Table cells contain Pearson's Correlation Coefficients.

$* *=$ Significant at the .01 level or better.

$*$ = Significant at the .05 level or better.

\begin{tabular}{|c|c|c|}
\hline $\begin{array}{l}\text { Obj. } \\
\text { Acco. }\end{array}$ & $\begin{array}{l}\text { Bene- } \\
\text { fit }\end{array}$ & $\begin{array}{l}\text { Org. } \\
\text { Perf. }\end{array}$ \\
\hline $.26^{*}$ & NS & NS \\
\hline NS & $.43 * *$ & $.35^{* *}$ \\
\hline $.29 *$ & NS & NS \\
\hline $.39 * *$ & NS & NS \\
\hline NS & NS & NS \\
\hline $.44 * *$ & NS & NS \\
\hline $.37 * *$ & NS & NS \\
\hline $.42 * *$ & $.38 * *$ & $.28 *$ \\
\hline NS & NS & NS \\
\hline NS & $.39 * *$ & $.28 *$ \\
\hline NS & NS & NS \\
\hline $.27 *$ & NS & NS \\
\hline $.37 * *$ & $.22 *$ & NS \\
\hline $.38^{*}$ & NS & NS \\
\hline $.29 *$ & NS & NS \\
\hline $.25^{*}$ & NS & NS \\
\hline $.44 * *$ & $.25^{*}$ & NS \\
\hline NS & $.46 * *$ & $.27 *$ \\
\hline $.34 *$ & NS & NS \\
\hline $.45^{* *}$ & NS & NS \\
\hline NS & NS & NS \\
\hline NS & $.33 *$ & $.22 *$ \\
\hline $.45 * *$ & $.28^{*}$ & $.31 *$ \\
\hline $.24 *$ & $.41 * *$ & NS \\
\hline $.26^{*}$ & NS & NS \\
\hline $.48 * *$ & NS & NS \\
\hline
\end{tabular}

\section{Rating BPR Benefits, And Antecedent Success Factors}

Table 3 shows that, on the average, the greatest benefits from BPR are reported in conjunction with human resources improvements (improved employee morale and productivity), and quicker response to customer requests. Improvements in the use of information technology to 
quickly address customer changes, on the average have occurred only to a minor extent. While the relatively large standard deviations indicate that individual companies show considerable differences in terms of their BPR derived benefits. Nevertheless, on the average, the companies participating in this study are getting all the benefits listed, at least to a minor extent. According to Table 6, the important success factors for deriving more benefits from BPR projects are having the project motivated by customer demands and competitive pressures, targeting only a few critical business processes, using hands on experience in reengineering processes, and focusing on outcomes rather than tasks.

\section{Rating BPR Impact on Company Performance, And Antecedent Success Factors}

Based on Table 4, on the average BPR has had less than an impressive impact on company performance. On the other hand, despite all the turmoil it many times creates within organizations, the downsizing often associated with it, and pressures it imposes on company personnel, BPR on the average seems to perform as a mild tonic for personnel development. Similarly, on the average it has helped to a moderate extent company operating profits, cost reduction programs, and cash flow from operations. Again, the relatively large standard deviations tell us that the impact varies considerably from company to company suggesting that its implementation can be quite risky depending on company, application, and project management circumstances. According to Table 6 , the important success factors for increasing the likelihood of positive BPR impact on company performance are having the project motivated by customer demands and competitive pressure, and to a lesser extent (lower coefficients significant at the .05 level or better); targeting only a few critical business processes, reducing costs and response times by automation, using hands-on experience for reengineering processes, using process mapping to identify value added activities, and revising procedures which satisfy internal requirements rather than the marketplace.

\section{CONCLUSIONS, IMPLICATIONS \& MANAGERIAL RECOMMENDATIONS}

In general, the results indicate that organizations are not emphasizing some of the most important goals and objectives recommended in the BPR literature, such as ensuring the valueadded element of every business activity, and applying the right innovative technology. While many individual organizations have reported major benefits and significant favorable impact on organization performance, on the average, benefits and company impact from BPR seem rather disappointing compared against all the turmoil it seems to generate. Before embarking on a BPR adventure, executives should ensure that at least some of the success factors deemed very important by the respondents are operational: the project is initiated and led from the top down by senior level managers, revise procedures addressing internal demands instead of the company's markets/customers, develop a defined project organization, use resources effectively, focus on outcomes rather than tasks, have regularly scheduled meetings between the project manager and each level of the project structure, share and exchange information willingly, and ensure that chief executive is willing to take responsibility for the project success. While on the average some of the success factors have received lower ratings, those with large standard deviations should be further considered since at least some of the respondents perceive them as very or extremely important from their perspective.

The results show that reeducating and retraining workers on what BPR actually is, on the average is deemed more important than empowering the workers performing the required tasks as decision makers. Superficially this contradicts one of the major tenets of organizational learning and TQM, however, a possible explanation for this apparent contradiction is that under the time pressure of a BPR project very likely workers had no time for learning the skills necessary to assume decision making responsibilities. Furthermore, worker empowerment 
seems to be a stronger determinant of BPR success (objectives accomplished) than educating/training them on the nature of BPR.

The results speak loudly about the need for authors to clearly define what they mean by BPR success before enumerating any list of factors considered important for successful implementation. Clearly, some of the factors studied here, such as the need for targeting only a few critical business processes per project and for revising procedures which cater to internal requirements rather than the marketplace, seem important to all three definitions of BPR success. However, most of the factors are important to only one or two of the success measures. This indicates that, while all three measures are important, they have dramatically different natures. In other words, its is possible that a particular BPR project completely met its goals and objectives without producing major business benefits due to customers or competitors reaction. Similarly, many of the projects where the success factors are associated with significant accomplishment of goals and objectives (and benefits), failed to produce significant positive impact on company performance. Perhaps one can assume a hierarchy of success measures with the accomplishment of project goals and objectives being at the lowest level: critical to project managers but relatively unimportant from a strategic perspective, thus not enough to significantly affect overall company performance, the highest level. Some of the goals and objectives seem strategically important, such as increasing competitiveness by reducing costs, but market dynamics and other factors may dilute the impact on company performance while accomplishing this objective. Similarly, the benefits from the BPR project may be considerable, but can also be diluted over time by a host of other variables. Thus, it behooves top managers to identify these variables affecting specific BPR projects, and include as part of the project goals and objectives preemptive measures. For example, if competitors are expected to react to a BPR project with a similar project, one of the goals should be to preempt such move and make things more difficult for the competitor. Most if not all the BPR projects described in the literature neglected to consider the extended market reaction to the project. Most carefully considered only the immediate reaction of direct beneficiaries (i.e. customers, suppliers or partners) or guessed at the results.

\section{Study Limitations and Future Research Requirements}

While this study's major objectives were accomplished, it has some limitations which should be viewed as opportunities for future research. The absence of any established BPR theory capable of producing results significant for business practice has forced the author to develop a conceptual framework mostly based on industry experience. While the measures were considered valid by practitioners test-piloting the questionnaire, and construct internal reliability were found to be satisfactory, further statistical analysis should be undertaken to identify subconstructs and, in turn, assess their reliability. There is need for longitudinal studies to explore the cause and effect relationships between variables. Last, multivariate statistical analysis should be conducted to explore possible relationships among the independent variables and clearly identify their mediating and moderating effects. Despite these limitations, this study makes a significant contribution as a first attempt at empirically testing the antecedents of BPR success.

\section{REFERENCES}

Bozman, J. S. (1992-1993) Downsizing, rightsizing, somethingsizing. ComputerWorld, 6-10. Brown, W. B. (1993) Leading the way to faster new product development. Academy of Management Executive, 7, 36-47.

Cafasso, R. (1993a) Rethinking reengineering. ComputerWorld, 102-105.

Cafasso, R. (1993b) Jean genies. ComputerWorld, 99-102.

Carmines, E. G. and Zeller, R. A. (1979) Reliability and validity assessment. Sage University Paper. 
Cascio, Wayne F. (1993) Downsizing: what do we know? what have we learned?, Academy of Management Executive, 7, 95-104.

Cummings, J. (1993) Reengineering falls short of expectations, study finds, Network World, 27.

Curtis, B., Kellner, M.I. and Over, J. (1992) Process modeling. Communications of the ACM, 75-90.

Cypress, H.L. (1994) Reengineering. OR/MS Today, 21, 18-29.

Dagres, T. (1993) Network reengineering for competitive advantage. White Paper.

Davenport, T.H. and Short, J.E. (1990) The new industrial engineering: information technology and business process redesign. Sloan Management Review, 31, 11-27.

The Economist (1993) Take a clean sheet of paper. The Economist, 327, 67-68.

Faier, J. and Shen, D. (1992) A telecom game plan for the 1990s, Telephony, 31-37.

Faltermayer, E. (1993) Invest or die. Fortune, 42-52.

Farmer, J.R. (1993) Reengineering the factory. APICS, 38-42.

Fitzpatrick, E.W. (1992) Information management. Journal of the American Society of CLU and $C h F c, 34-35$.

Freiser, T. J. (1992) The right start for business reengineering, Information Strategy: The Executive's Journal, 26-30.

Goll, E.O. and Cordovano, M.F. (1993) Construction time again. CIO, 32-36.

Gotlieb, L. (1993) Information technology. CMA Magazine, 67, 9-10.

Green, C. (1992) Quality improvement-from dreams to reality. Canadian Business Review,3337.

Grover, V., Teng, J.T.C. and Fiedler, K.D. (1993) Information technology enabled business process redesign: an integrated planning framework. OMEGA, 21, 433-447.

Guimaraes, T. (1995) Empirically assessing the impact of BPR on manufacturing firms. International Journal of Operations and Production Management, forthcoming.

Guimaraes, T. (1993) Managing expert systems technology and business process reengineering. Symposium of the Information Processing Society of Japan, Tokyo, 1993.

Guimaraes, T., Bell, R.E., and Marston, R.(1993) Organizing for innovation. Fourth International Forum on Technology Management, Berlin, Germany, October 18-20, 1993.

Gulden, G.K. and Reck, R.H. (1992) Combining quality and reengineering efforts for process excellence. Information Strategy: The Executive's Journal, 10-16.

Gupta, Anil K. and Govindarajan, V. (1984) Business unit strategy, managerial characteristics, and business unit effectiveness at strategy implementation. Academy of Management Journal, 27, 25-41.

Hammer, M. (1990) Reengineering work: donflt automate, obliterate. Harvard Business Review, 104-112.

Hayley, K., Plewa, J., and Watts, M. (1993) Reengineering tops CIO menu. Datamation, 7374.

Howard, J.S. (1994) Reinventing the manufacturing company. D\&B Reports, 18-21.

Huff, S.L. (1992) Reengineering the business. Business Quarterly, 38-42.

Kador, J. (1992) Reengineer to boost software productivity. Datamation, 57-58.

Knorr, R.O.. (1991) Business process redesign: key to competitiveness. The Journal of Business Strategy, 48-51.

Margolis, N. (1992/1993) Voices of experience. ComputerWorld, 16-17.

Miske, J.C. (1992) Reversing the decline of manufacturing in America. Foundry Management

\& Technology, 17.

Moad, J. (1993) Does reengineering really work. Datamation, 22-28.

Nunally, J. C., (1978) Psychometric theory., McGraw-Hill, New York, NY, 1978.

OflLeary, M. (1993) A new life for purchasing. CIO, 32-41.

Oliver, W.H. (1990) The quality revolution. Vital Speeches of the Day, 625-628.

Patterson, M.C. and Harmel, R.M. (1992) The revolution occurring in American Manufacturing. $I M, 15-17$. 
Ramberg, J.S. (1994) TQM: thought revolution or Trojan horse? OR/MS Today, 2, 18-24.

Rasmus, D. (1992) 'Reengineering,fl or evolution through violent overthrow. Manufacturing Systems, 10, 52-58.

Snow, C.C. and Hrebniak, L. (1980) Strategy, distinctive competence, and organizational performance, Administrative Science Quarterly, 25, 317-335.

Stadler, D.A. and Elliot, S.A. (1992) Remake your business, Inform, 2-17.

Steers, R.M. (1977) Organizational effectiveness: a behavioral view, The Goodyear series in management and organizations, Santa Monica, CA: Goodyear Publishing.

Teng, J.T.C., Grover, V. and Fiedler, K.D. (1994) Business process reengineering: charting a strategic path for the information age, California Management Review, 36, 9-31.

Tsang, E. (1993) Business process reengineering and why it requires business event analysis, CASE Trends, 8-15.

Venkatraman, N. and Ramanujam, V. (1986) Measurement of business performance in strategy research: A comparison of approaches, Academy of Management Review, 11, 801-814.

Yoon, Y., Guimaraes, T. and O'Neal, Q. (1995) Exploring the factors associated with expert systems success, MIS Quarterly, 19.

Yoon, Y., Guimaraes, T. and Clevenson, A. (Forthcoming) Factors important to expert systems success: A field test, Information \& Management.

\section{BIOGRAPHY}

Tor Guimaraes is the director of the Institute for Technology Management and holder of the J.E. Owen Chair of Excellence at Tennessee Technological University. He has a Ph.D. from the University of Minnesota and an M.B.A. from California State University, Los Angeles. He was a Professor and Department Chairman at St. Cloud State University. Previously, he was Assistant Professor and Director of the MIS Certificate Program at Case-Western Reserve University. He has been the keynote speaker at national and international meetings sponsored by organizations such as the Information Processing Society of Japan, Institute of Industrial Engineers, American Society for Quality Control, IEEE, ASM, and Sales and Marketing Executives. He has consulted with many leading organizations including TRW, American Greetings, AT\&T, IBM and the Department of Defense. With his partners throuhgout the world he has published over one hundred articles on technology management in leading journals. 